\title{
Study on the Triple Reflections of Liberal Nationalism on Global Justice
}

\author{
Hailong Liu \\ School of Philosophy \\ Wuhan University \\ Wuhan, China 430072
}

\begin{abstract}
As a political force that can't be no neglected in today's international political structure, the nation-state has an important influence on the promotion of the concept and value of justice in a global scale. However, global justice theorists represented by cosmopolitanism always have prejudice and misunderstanding about the nationalist political concepts. In fact, liberal nationalism does not impede the promotion of justice. Instead, it points out the problem of the global justice theory more effectively and helps to establish the principle of justice in a wider range. We should reflect on the issue of global justice around the three main aspects of the theory of justice, the principle of distribution and the predicament of globalization through the perspective of liberal national politics and try to explore the prospect of global justice on the basis of recognizing political reality.
\end{abstract} justice

Keywords—liberalism; cosmopolitanism; nationalism; global

\section{INTRODUCTION}

Nationalism" was once defined by Ernest Gelner as a "theory of political legitimacy" [1], which profoundly reflects the national character that cannot be ignored in the process of changes of the political concepts of human society, including the value of justice. For a long time, however, the global concept of justice and national political views have often been misunderstood as a set of values that are mutually contradictory. In contemporary political philosophy, this opposition manifests prominently as the controversy between liberal cosmopolitanism and liberal nationalism. 1 In the international political reality, it presents as the contradiction between the particularity of the present state of the nation state and the universality of the demand of global justice, which means "the world of human civilization differentiate politically into the contradiction between a regional sovereign state and its globalization in technology and economy"[2]. In fact, if we completely deny and adopt a hostile attitude towards nationalism, it will be detrimental to both domestic adopt a hostile attitude towards and international justice. Therefore, we must envisage the

Not all scholars recognize global justice. In addition to criticism from realism, libertarianism and communitarianism, they have to be faced with the query of liberal nationalists represented by David Miller within egalitarianism. They neither suspect egalitarianism nor belittle international moral values, but maintain a cautious attitude toward global justice. appropriate nationalism, recognize the fact that the nationstates serve as an important force in contemporary politics and seek the possibility of prospect of justice while reflecting on the global dilemma of justice.

\section{NATIONALISM: The Misunderstood PolitiCAL REALITY}

Contemporary national politics theory is often regarded as incompatible with the concept of justice. However, this concept only sees the problem of some extreme nationalism and wrongly contradicts it with the liberal political concepts, shaping the contradictory relationship in which the two concepts are incommensurable. The ideological root of this misunderstanding lies in the externalization of the national political image by the traditional political stance. It not only ignores the reality of the international political structure, but also ignores the importance of nation states in popularizing the concept of global justice.

Since the Enlightenment, the impetus of modernity has driven people out of their social roles and traditional identities. The breaking of shackles in the real world and the spiritual world has led people to agree on a "concept of human progress" with cosmopolitanism. Condorcet believes that our culture will converge based on a unified language and progress will enable the "backward" minorities to be integrated into the "more energetic" mainstream groups. [3] This concept of cosmopolitanism, which emerged in the Eeagan era, gradually gained its liberation and development in the Enlightenment. It believes that the integration and sharing of economy, culture and politics in the world will lead to the emergence of a unified political alliance and the disappearance of national identity will follow. Viewed from the political division of national superiority and inferiority contained in the concept of human progress, this hegemonystyle political unification not only fail to maintain multiple values in culture but also fails to respect and safeguard the rights of self-determination of minorities and ethnic minorities.

In fact, what need to be pursued by global justice are not the eliminating cultural differences but opening up national identity so that different cultural groups can approach each other. The problem with cosmopolitanism lies in the conclusion that the end of a traditional nation-state will be counterproductive. And in the process of political 
assimilation, it is often able to arouse the highlight of nationality resistance and self-awareness. If we inspect the value standpoint of cosmopolitan from the political perspective of nationalism ${ }^{2}$, global justice is precisely a kind of self-talking "Great Harmony" thought of west-centralism that not only harms national self-determination, national responsibility and national identity ${ }^{3}$, but also a kind of compulsion and injustice without soliciting the informed consent of all ethnic groups, which always leads to conflict of nationalism predicament and thus causes the dilemma and problem of consensual identification of political consensus among the nations.

The direct reason why cosmopolitans cannot understand nationalism is that they do not recognize the differences between countries and cultures, and thus exclude the support of specific national identity and culture and only exist on the principle of global justice. The power of nationalism stems from the common culture and historical accumulation in the national political context. In this historical process, social ethics and moral values continue to accumulate and evolve, so that they are gradually recognized and derive a common concept of justice. Only by settling the political identity basis of establishment of the theory can global justice have the possibility of value promotion and the effectiveness of its implementation, and then proceed with the construction of specific strategies. If integrative ideas and responsibilities are excessively emphasized without the identification base of the majority of members to some extent, nationalism, of which the living space is squeezed, can only choose the other way. For example, the Brexit event is precisely not the so-called restoration of ultra-nationalism. National consciousness has always existed, but it is the stress response due to external stress after being subjected to long-term disregard and prejudice.

Therefore, it cannot be denied that nationalism is still the long-standing political force in the process of globalization since the current world culture cannot provide substantial collective conviction and value that can only be provided by nationalism as a "religious substitute." [4]Kim Ricard holds that liberal nationalism will redefine cosmopolitanism whose real enemy should be the ideas such as exclusion, intolerance, injustice, great-power chauvinism, militarism, and colonialism and so on and these characteristics are not the necessary conditions for nationalists, so there is no reason to affirm that liberal nationalists cannot possess the virtues of cosmopolitanism. Therefore, liberalism should consider global justice in a realism way. The liberal nationalist principles, however, do not deny that freedom and rights are

Although there are differences in types in cosmopolitanism, different cosmopolitan propositions contain three elements in common: 1 . Individualism, the basic unit of care is individual, instead of family, tribe, (race, Cultural or religious) communities, nations and countries. 2 . Universality, all individuals who are cared are equal. 3. Generality, universal requirements are applicable worldwide. See details in Thomas W Bogge, Cosmopolitanism and Sovereignty, Ethics, Vol. 103, No.1, 1992, p.48.

Nationalists believe that global justice hurts national selfdetermination, ethnic responsibility and national identity. See details in Gao Jingzhu: "Commentary on the disputation of Nationalism and Global Justice", National Studies, No.3, 2016, pp. 6-8. concerns that individuals can develop and express the identities of other groups. Instead, it has cleared the way to global justice for emotional identification of individuals. [6]

\section{The FIRST REFLECTION ON GLOBAL JUSTICE: THE JUSTICE OF DIFFERENCE}

Based on the nationalist political outlook, David Miller profoundly examines the historical evolution of justice and holds that social justice, which generates changes and develops in the soil within the nation-state, cannot be simply applied to the international community. However, the cosmopolitan is not satisfied with the conception of RawlsUtopian society of peoples and they are trying to apply the principle of differences in domestic justice more widely to the international community ${ }^{4}$. Although the idea of global justice is based on the development of the theory of justice, the basis for the establishment of the values of global justice and social justice still exists.

The justice we speak in everyday context is often based on a limited prefix: society. ${ }^{5}$ The origin of justice can be traced back to the ancient Greek city-state community which was shaped by the early modern order society. Solon first introduces the meaning of "legitimate" into justice, which is used to solve the disputes of urban community. Plato, on the other hand, believes that righteous people preserve the virtues of "doing their own things without interfering with others" in the city life. Aristotle neutralizes the two and speaks of justice and friendliness in the life of citizens. In the medieval Christian world, justice is manifested in the judgment about the good and the evil in the eschatology. In the modern era, the issue of justice started with the theory of natural law. People began to attach importance to the concept of rights and gradually the theoretical foundation of the concept of liberal justice is generated. Until the late 1970s, Rawls began to propose "fair justice" and through the continuous development and integration of history, the theory of human justice has truly incorporated the elements of substantive equality into the notion of a fair social cooperation system and becomes a kind of "synthesis of concept of justice within the framework of liberalism" [7].

It can be said that social justice was derived from the community life in early stage and tried to solve the moral problems in the internal life of the community. Since the Treaty of Westphalia was reached in 1648 by all European countries, after the bourgeois revolution and the national independence movement, there has been a worldwide political structure with the nation-states as the main components ${ }^{6}$. Therefore, social justice mainly takes the main

\footnotetext{
$4 \quad$ Beitz proposes to apply the principle of difference in Rawls's
} theory of justice to the international level. See details in C. Beitz, Political Theory and International Relations, Princeton: Princeton University Press, 1979, pt. III.

Rawls talked about justice, distributive justice and social justice in the theory of justice without distinction, and in generalized connotation of justice, these terms mean approximately universal.

$6 \quad$ Nation-state first appeared in sovereign state that was born during the process of getting rid of the control of magisterium in Western Europe, which refers to the political entity of the self-determination and autonomy of modernity. Generally speaking, the sovereign states that 
nation-states as the scope of application. According to Rawls, the principle of justice is used in a closed system society, as it states: "This society is self-contained and has no connection with other societies. We just live and die." Specifically, the legitimacy of the existence of social justice is based on deep national character, historic nature and cultural responsibilities and obligations. Miller believes that if the concept of justice makes sense, we must assume that there is wide consensus of social values of goods, services, opportunities in a certain range. [9] That is, justice is a concept determined by a specific situation. There is no principle that can define justice completely at any time and place. Instead, the development of the relevant principles relies on clarifying what is to be distributed, who should allocate, and to whom. It especially depends on the type of relationship among those involved.

In addition, Miller gives three levels of consideration to illustrate the nationalism particularity of justice. [10]First, ethnic identity tends to create a solid bond of solidarity among people under the same comprehensive doctrines, forming the basis for the relationship of the principles of justice. Second, ethnic political culture contains the range of understanding enjoyed by the fundamental context in which the principle of social justice is formed. When people ask if the enjoyment of resources available is fair, their own community is a natural reference group. For example, when we compare incomes and distributions, we usually compare them with other people in the same political system, usually within a nation-state. Finally, the nation-state guarantees the validity of justice and enables people to be convinced that the constraints for them in following fairness principles and procedures are equally valid for everyone else. That is to say, such obstacles pose a restriction on people's actions only when others or agencies are responsible for the obstacles limiting themselves. This conviction of justice can only be guaranteed in the nation-state because the unity of nationstates provides the basis for mutual trust. In addition, more importantly, it provides a coercive measure that injustice is punished at the national level, which is difficult to be guaranteed at the international level.

\section{The SeCOnd Reflection on Global Justice: The INTERROGATION OF DISTRIBUTIVE JUSTICE}

With the increasingly prominent problems of inequality caused by the global economic development in modern times and the ever-increasing exchanges and information sharing among different ethnic groups and countries and regions, people's concern about the issue of justice is no longer confined within the nation-state and gradually begins to gradually expand to the problem of inequality around the world. The cosmopolitans represented by Pogge and Beitz enthusiastically transformed Rawls's theory of justice and tried to come up with solutions to the problem of global justice. However, from the perspective of theoretical basis,

scholars generally talk about are generally the nation-states. Wharton said that the United Nations is not so much the unification of sovereign states as the unification of the nation-states. See details in H. Seton-Watson, Nations and States: An Enquiry into the Origins of Nations and the Politics of Nationalism, London: Methuen, p.1-2. the principle of justice cannot simply cross the nation-state and directly rise to the global level. However, the strategy of global distributive justice given by the cosmopolitan in reality also faces the challenge from the nationalists.

Pogge's theory of global distributive justice holds that the difficult situation of poor countries is constrained by the natural impoverishment and historical oppression and exploitation and attempts to solve the global poverty problem by using the dividend program of global resources. However, this explanation cannot support the source of the legitimacy of "justice obligations" of all rich countries for poor countries. Factors for rich and poor are complicated and changeable. Rawls thinks that not all wealth inequalities are originated from injustice [12]. If the root causes of national poverty are all attributed to external factors such as "resource curse" and "external oppression", it is obviously too arbitrary. Equally, not all rich countries' wealth is derived from the abundance of natural resources and the historical plundering of other nations. Before addressing the problem of global poverty, it is urgent to examine the underlying causes of inequality and imposing strong obligations of justice excessively on other countries is not reasonable. Based on this consideration, Miller explicitly rejects Beitz's application of the difference principle to the international level. It also outlines a picture of international justice based on the selfdetermination of nation-states and respecting the selfdetermination of other nations through non-interference with their obligations and assistance obligations. [13]

To a certain extent, Rawls expressed his rejection of the principle of global distributive justice and held that international aid obligations should be regarded as humanitarian instead of cosmopolitan for it not only satisfied the minimum standards that should exist but also satisfied the conditions necessary for the self-determination of the national community. Because the issue of inequality and poverty involves a wide range with complex situations in the global arena, a cautious justification is more appropriate to be promoted. The nation-state can have the right to refuse the aid or live the life that they expects but different from the other. Since humanitarian aid obligations are more in line with the moral justice, they prefer to have strong humanitarian aid obligations rather than have (even if) weak coercive distribution principles. ${ }^{7}$ If it is assumed that the "obligation of justice" has become a distribution system with mandatory feature, some countries may rely on "justice assistance" excessively and the issue of poverty can hardly be solved at root.

In addition, the principle of non-interference and respect for self-determination of nations also prevented the rich countries from controlling over the politics, economy and

Martin argues that although Rawls's argument in the Law of the People is considered weak, it does not mean that he must recognize his critics and endorse a stronger version of the principle of global disparity. However, some of the objectionable arguments he had made were developed in Rawls's deep-seated theories of thought. These arguments are also valid. See details in R. Martin. Rawls on International Distributive Economic Justice: Taking a Closer Look, in Rawls's Law of Peoples: A Realistic Utopia? R. Martin, D.A. Reidy（ed）, Willy-Blackwell Press, 2006, p.237. 
culture of poor countries in the name of aid, resulting in new inequalities. The "Americanism" carried out by the U.S. government in its foreign policy today is an act of wearing a justice outerwear to expand the national interest of the United States around the world and promote the national value of the United States. This behavior is based on the concept of "centralizing their own worldview to feel the distant world beyond its borders" and is described by Habermas as a "universalism of the old empire" [14]. Besides, global distributive justice aims at safeguarding individual rights, but global distributive justice cannot realize the atomized distribution according to the principle of equality and justice. That is, it is unable to achieve more efficient and more targeted individual aid obligations by bypassing the nation-state. Moreover, there are differences in living standards and criterion in each country and individuals cannot prove the legitimacy of international distribution through secondary distribution at the national level.

\section{THE THIRD REFLECTION ON GLOBAL JUSTICE: THE DILEMMA OF JUSTICE IN THE PROCESS OF GLOBALIZATION}

The contemporary global political reality is manifested in two aspects. On the one hand, it is an international political structure dominated by nation-states. On the other hand, it is the continuous development of globalization and the inequalities caused by development. In fact, there are two deeper problems lurking in the world's political reality in the context of globalization. One is the conflict between domestic identity and international identity in the context of global justice. The other is the dilemma of justice in the globalization and cultural pluralism.

For people, the essence of justice is to protect the rights of free voting rights, free expression right and minimum material resources, so that they can effectively fulfill their political role of citizens, which can only be achieved in a complete political system. However, Miller believes that the order of people's emotional preferences and psychological recognition is from the inside and outside, and the order of identify is from the nation to the world. In the world pattern dominated by nation-state, it is unrealistic to make international recognition even or exceed domestic recognition. Therefore, no matter from political experience or political fact, a state of political unity in the world can be reached. The cosmopolitan once tried to respond to Miller's question with negative obligations, but they eventually had to admit this dilemma ${ }^{8}$.

\footnotetext{
8 Under normal circumstances, it is acceptable to have more obligations to family members than neighbors, have more obligations to compatriots than the foreign nations. Bogge tried to quote negative obligations to show that when human rights are violated and preferences are conflicted, any preference must be excluded. Difference between close and distant does not affect the obligations, and we must maintain justice. However, they later thought that their refutation was too strong, and acknowledged that special relation and special causes would weaken the clients' obligations to strangers far away. See details in Thomas Pogge: "Kant, Rawls and Global Justice", tr. Liu Xin, Xu Xiangdong, Shanghai: Shanghai Translation Publishing House, 2010, 541-542 pages. In fact, this article considers it important that Bogge does not consider that there is still a conflict between the obligation of justice and favoritism if the cause of the violation of non-nationals does not have any relation with one's own
}

In the international community, the ever-increasing mobility of capital and labor force especially high-level labor brought by globalization and boundless rapid flow of information, often have an impact on national justice. When a country attempts to safeguard economic justice, increase social responsibility for capital commitments, raise labor compensation to safeguard workers' rights and interests, o levy tax on some high-income groups, it will find the international transfer of capital and high-income groups will choose to live in the countries with low cost and high returns. Unless a country is completely isolated from globalization, it will inevitably suffer losses in the maintenance of social justice. In fact, the system of social justice presupposes an economic code that supports itself. At the same time, the principle of global justice requires that every country follow the freedom and equality of global markets, so the two will inevitably clash.

On the other hand, globalization has brought the fragmentation of national culture and the rise of emerging cultural groups. In a sense, the intercultural communication and dissemination have broken through the existing norms and developed towards an interactive form of inundation and invasion, resulting in the fracture of unified identity of the internal cultural tradition and bringing the mess of internal politics and cultural participation. According to Cooks, this cultural diversity does not impede the possibility of moral criticism and/ or development of universal moral knowledge, nor does moral diversity mean that we lack the rational basis of minimal international virtue. [15]Kurt intends to point out that the characteristics of global cultural diversity do not hinder the shaping and development of global justice. However, this is not the case. The principle of global ethics involves only the minimum content, but it fails to meet the realistic requirements of the concept of global justice, let alone establishing an effective system of global distributive justice. In general, cultural globalization has had a negative impact mainly on the three aspects of the relevance of justice, the importance of justice and the consensus of justice.

First of all, we cannot regard the realization of the principle of justice as inevitable. Such institutions and reforms are relevant to them only when different cultural groups and justice implemented within cultural groups are considered. Second, the overflow of global cultural diversity has the consequence of replacing the traditional concerns of material distribution (the distribution of social products or the state's participation in the supply of goods and services). Fraser argues that "when society becomes multi-culture, the political sharpness of the material distribution problem will be sharply reduced and replaced by cultural recognition." [16]In simple terms, overflow of cultural diversification will reduce the importance of the issue of justice. Although cultural recognition, broadly speaking, is still a political issue in a broad sense, it is no longer the problem of distributive justice that is concerned about by political philosophers from Mill to Rawls. Finally, cultural diversity makes it hard for people to see themselves as members of a broader

family or one's own compatriots. In fact, people often choose the side they prefer. 
community, making it more difficult for people to reach a political consensus of global justice.

\section{CONCLUSION}

Based on the liberal nationalist political stance, this paper examines the predicament of global justice in three dimensions. In fact, global justice not only lacks a status of political unification, but rather the problem is that even common political principles is not enough to bring about reunification. Norman argues that the key to political unification lies not in shared political values but in shared sense of political identity. [17]This political identity contains common values, including language, history and culture, which can provide the value basis for the principles of global justice. However, in reality, the concept of global justice not only lacks extensive support and action, but also can easily be manipulated as a theory of justice for a certain class or a country rather than a universal value. He Baogang believes that the fundamental problem of global justice now lies in the lack of emphasis on local justice. Most of the theories of global justice only extend the theory confined to the nationstates to the world. This framework has limited people's thinking. In the process of popularization, the theoretical idea of western justice center has hindered the emphasis on cultural equality and local justice. The current debate over global justice belongs to the controversy within the Western theory of justice. Under such a situation dominated by Western discourse, it is simply impossible to place the concern truly at the global and regional levels. [18]

For China, we should discern the nature and attribution of contemporary global justice theory more rationally. At the same time, we must have our own political philosophy to reflect on the most basic codes of mutual communication in human society, to participate more in the action of global affairs and the theoretical discussions of global justice. Otherwise, China's political philosophy can only be "the geographical distribution of Western political philosophy, and there is no other justified basis" [19]. Especially at the present times, as Marx puts it, "the regional and national self-sufficiency and self-reliance in the past have been replaced by the interaction and interdependence of all aspects of the nation. The one-sidedness and limitation of the nation are becoming impossible"[20]. As an important part of the world's political forces, we must, in accordance with the spirit of the times, come up with the concept of global justice with Chinese characteristics and break the arbitrary of western theories. General Secretary Xi Jinping once again emphasizes the concept of "human destiny community" at the high-level dialogue meeting of political parties in the world and calls on all the nation-states all over the world to jointly establish a view of destiny sharing joys and sorrows and promote the building of a new type of international relations to provide a brand new value basis and practice path for building of global justice system.

\section{REFERENCES}

[1] Emest Gellner, Nations and Nationalism, Oxford: Basil Blackwell. 1983, p.1.
[2] Arnold Toynbee. Mankind and Earth Mother [M]. tr. Xu Bo et al Shanghai: Shanghai People's Publishing House, 1993: 725.

[3] Condorcet. Outline of the progress history of human spirit [M] tr. $\mathrm{He}$ Zhaowu. Nanjing: Jiangsu Education Publishing House, 2006: 178.

[4] Anthony D. Smith. Nationalism and Nation in the Era of Globalization $[\mathrm{M}]$ tr. Gong Weibin, Liang Jingyu. Beijing: Central Compilation and Translation Press, 2002: 210.

[5] Will Kymlicka. Minority Rights: Nationalism, Multiculturalism and Citizenship [M]. tr. Deng Hongfeng. Shanghai: Shanghai Translation Publishing House, 2005: 235-237.

[6] David Miller. On nationality [M] tr. Liu Shuhui translation. Nanjing Yilin Press, 2010: 156,107.

[7] Liao Shenbai. Concept of Western justice: the synthesis of evolution [J] Philosophical Research, 2002,11: 66.

[8] J.Rawls, Political Liberalism. New York: Columbia University Press, 1993, p. 68.

[9] David Miller. National Responsibility and Global Justice [M] tr. Yang Tong. Chongqing: Chongqing Publishing House, 2014: 18.

[10] David Miller. The principle of social justice [M] tr. Ying Qi. Nanjing Jiangsu People's Publishing House, 2001: 29-30.

[11] Thomas W. Pogge. An Egalitarian Law of Peoples, Philosophy and Public Affairs, Vol.23, No.3, 1994, p. 195-224.

[12] John Rawls. The Law of Peoples, Cambridge and London: Harvard University Press, 1999, p. 107-113.

[13] Jurgen Habermas, Was bedeutet der Denkmalsturz? Frankfurter Allgemeine Zeitung vom 17, April 2003, p. 33f

[14] Chandran Kukathas. Are There any Cultural Rights? Political Theory, 1992, 20(1), p. 105

[15] N. Fraser, From Redistribution to Recognition? Dilemmas of Justice in a "Post-Socialist" Age, New Left Review, Vol. 212, 1995(7-8), pp. 68-93.

[16] W. J. Norman.'The Ideology of Shared Values', in Joseph Carens(ed.), Is Quebec Nationalism Just? : perspectives from Anglophone Canada, Montreal : McGill-Queen's University Press, 1995, pp.137-59.

[17] He Baogang. Three Global Views of Justice: A Critique of the Global Justice Theories by Local Justice [C] // Xu Jilin, Dialogue between Global Justice and Civilization. Nanjing: Jiangsu People's Publishing House, 2004: 82.

[18] Han Shuifa. The Vision of Justice - Political Philosophy and Chinese Society[M] Beijing: The Commercial Press, 2009: 66.

[19] Selected Works of Marx and Engels (Volume I) [M]. Beijing People's Publishing House, 1995: 254-255. 